\title{
OS SUJEITOS SOCIAIS GRUPOS FAMILIARES E A (RE)SIGNIFICAÇÃO DO CURRÍCULO DA EDUCAÇÃO DO CAMPO
}

\author{
(The family groups and the re-meaning of the \\ country side education curriculum)
}

Neusa Inês Philippsen ${ }^{1}$

Maria de Fátima Castilho ${ }^{2}$

(Universidade do Estado de Mato Grosso - UNEMAT)

\begin{abstract}
This article mobilizes the theoretical and methodological devices of the Discourse Analysis from the theoretical French line and apparatus about country education, such as the CNE - CEB Resolution number 01/2002 Operational Lines for Basic Education in country schools. We have carried out analysis about the discourses of the country social individuals in the Settlement of Agrarian Reform Gleba Mercedes V, located $95 \mathrm{~km}$ from Sinop/MT, more specifically of the family groups segment. As from the results obtained with this research, we expect to contribute with the reconstruction of the personal identity of the social individuals in the country potentializing them so that they can discover themselves as historical beings, constructors of multiculturalist curriculum for their legit participation in the educational process in their community.
\end{abstract}

Keywords: Discourse Analysis, family groups, curriculum, country education.

1. Doutoranda em Filologia e Língua Portuguesa na USP, professora de Língua Portuguesa e Linguística da Universidade do Estado de Mato Grosso-UNEMAT e pesquisadora integrante do Projeto SABERES DA TERRA: dos discursos dos sujeitos sociais à multiplicidade de saberes para a (re) significação do currículo da educação do campo.

2. Mestra em Educação pela Universidade Federal do Rio Grande do Sul, professora de Metodologia do Ensino Fundamental e do Ensino da Língua Portuguesa no Início da Escolarização e pesquisadora coordenadora do Projeto SABERES DA TERRA: dos discursos dos sujeitos sociais à multiplicidade de saberes para a (re) significação do currículo da educação do campo. 


\section{RESUMO}

Neste artigo, em que se mobilizam os dispositivos teóricos e metodológicos da Análise de Discurso (AD) da linha teórica francesa e aparatos sobre a educação do campo, tais como a Resolução n ${ }^{\circ}$ 01/2002 do CNE- CEB - Diretrizes Operacionais para a Educação Básica nas escolas do campo, realizamos análises sobre os discursos dos sujeitos sociais do campo, no Assentamento de Reforma Agrária Gleba Mercedes V, localizado a $95 \mathrm{~km}$ da cidade de Sinop/MT, mais especificamente do segmento grupos familiares. A partir dos resultados dessa pesquisa, esperamos contribuir com a (re)construção da identidade pessoal desses sujeitos, potencializando-os a se descobrirem como seres históricos e construtores de currículos multiculturalistas pela legítima participação no processo educativo na sua comunidade.

Palavras-chave: Análise de Discurso, grupos familiares, currículo, escola do campo.

\section{Entremeios discursivos: apontamentos iniciais}

Este artigo representa parte dos resultados obtidos pelos trabalhos realizados no Projeto SABERES DA TERRA: dos discursos dos sujeitos sociais à multiplicidade de saberes para a (re) significação do currículo da educação do campo, que teve o seu período de execução entre fevereiro de 2007 a fevereiro de 2010. Dentre os objetivos principais desse projeto, destacamos a ênfase em apreender, nas formulações discursivas integrantes do corpus, efeitos de sentidos que retratam a importância e as especificidades do campo pela multiplicidade de saberes, conhecimentos e experiências, que entrelaçam as práticas educativas escolares com a vida de homens e mulheres assentados para a construção social do currículo, vinculado à teoria pós-crítica e ao enfoque dos estudos multiculturais.

A proposta desse trabalho de pesquisa deveu-se, fundamentalmente, a dois grandes propósitos: o primeiro refere-se à continuidade e os diálogos produzidos entre as áreas de conhecimentos gerados nas e pelas pesquisas, como princípios científicos e ações 
sócio-culturais de intervenção na realidade atual; o segundo, refere-se à (re) significação do currículo escolar pela valorização da diversidade cultural e pluralidade de saberes.

A aplicação do método de estudo de caso foi realizada em duas escolas do Assentamento de Reforma Agrária Gleba Mercedes V - Núcleos Campos Novos e Agrovila, pertencentes ao Município de Sinop 3 , MT. O procedimento metodológico consistiu na coleta de material linguístico por meio da técnica de entrevistas semiestruturadas, realizadas a partir de blocos/eixos de questões. Os sujeitos sociais do campo selecionados para as entrevistas foram grupos familiares (trabalhadores e trabalhadoras rurais na posição de pais e mães de alunos ou alunas; presidentes de associações/cooperativas e alunos e alunas da Educação de Jovens e Adultos), professores e professoras, coordenadores e coordenadoras, e diretoras dessas duas escolas do campo.

Neste artigo, contudo, recortamos apenas um dos segmentos de sujeitos analisados, o segmento grupos familiares. Dentre os dispositivos teóricos e metodológicos utilizados, destacamos a Análise de Discurso (AD) da linha francesa e aparatos sobre a educação do campo. Sob essa ótica procuramos descrever e analisar a política educacional adotada nas escolas do citado Assentamento de Reforma Agrária.

Dessa forma, a pesquisa procurou enfatizar diferentes sentidos que circulam no entorno do Assentamento e que importam à construção de um currículo multicultural voltado para a Educação do Campo. Educação essa que compreendemos como afirmação, reconhecimento e valorização da multiplicidade de práticas sociais constitutivas dos sujeitos que vivem no campo, assim, buscamos entender quais são os saberes e conhecimentos produzidos pelos grupos familiares na relação com eles mesmos, com a terra e com a escola, na produção de discursos provenientes de diferentes formações discursivas.

3. Fundada em 14 de setembro de 1974, Sinop (Sociedade Imobiliária do Noroeste do Paraná) dista 503 km de Cuiabá, a capital do Estado, e tem uma população oficial de 111.643 habitantes (IBGE, 2010). 
Nesse contexto, a identidade ${ }^{4}$ da escola do campo encontra-se ligada à diversidade de saberes ${ }^{5} \mathrm{e}$ às múltiplas formas de geração e (re) criação de conhecimentos produzidos pelos sujeitos na comunidade em que vivem. Dessa maneira, ao se falar sobre identidade da escola do campo não se pode pensar tão somente nos saberes produzidos por esses sujeitos e evidenciados sob efeitos de sentidos daquilo que dizem e do modo como dizem, é preciso incorporar nesse conjunto toda rede de saberes produzida na interação com a memória coletiva ${ }^{6}$, com os movimentos sociais e com a bagagem sócio-cultural trazida por cada assentado e assentada.

É, portanto, a essa complexidade de discursos, saberes e sentidos, que lançamos o nosso olhar analítico com o propósito de mobilizar as Secretarias Municipal e Estadual de Educação de Sinop, bem como outras instituições no intuito de levá-las a contemplar nas políticas educacionais as particularidades históricas, sociais e culturais que diferenciam o campo da cidade.

\section{Alinhavos teóricos e metodológicos: fundamentações}

$\mathrm{Na}$ tentativa de apreendermos as particularidades acima descritas, apoiamo-nos nos pressupostos teóricos da Análise de Discurso francesa porque a entendemos como ruptura a gestos tradicionais de leitura e interpretação. Nesse sentido, a AD atende aos nossos propósitos de pesquisa visto que, para tal área de conhecimento, qualquer prática que envolva a produção da linguagem - na escola, e

4. A identidade é pensada, aqui, de acordo com a teoria de currículo pós-crítica, multicultural, no intuito de 'dar voz' a homens e mulheres do campo, representantes de culturas dominadas e excluídos socialmente.

5. Utilizamos a palavra "saberes" nessa pesquisa como referências à heterogeneidade de vivências e experiências dos sujeitos sociais do campo, à pluralidade de saber: educacional, profissional, cultural, social, e às formas de ser e de produzir sentimentos.

6. Memória coletiva remete, nesse contexto, à memória do dizer, ou seja, conforme Orlandi (2007), o significado do dizer é determinado pela língua e pela história de tal modo que os sentidos são sempre referidos a outros sentidos e é daí que eles tiram sua identidade. 
fora dela - apresenta três elementos como fundamentais na interação verbal: interlocutores, enunciados e mundo. Desse modo:

Falar, ler, escrever, citar, analisar, reproduzir, repetir, resumir, criticar, narrar, imitar, parafrasear, parodiar, etc. são práticas em que a linguagem enquanto discurso materializa o contato entre o lingüístico (a língua enquanto um sistema de regras e de categorias) e o nãolingüístico (um lugar de investimentos sociais, históricos, ideológicos, psíquicos), por meio de sujeitos interagindo em situações concretas (CARDOSO, 2003: p.11)

Para a AD, portanto, interessa o enfoque da linguagem sóciohistórico e cabe ao pesquisador-analista verificar a organização textual, os elementos que a constituem, as condições de produção do discurso e as situações em que o sentido é instituído.

É importante ressaltar também que a AD trata do discurso como palavra em movimento, no acontecimento. Estuda o discurso como incompletude, característica de todo processo de significação (Orlandi, 2001). Concebe, assim, a linguagem como não transparente e como mediação necessária entre o homem e a realidade natural e social. A linguagem é, então, considerada numa relação de dependência da sua situação concreta de produção, pois se realiza na interação verbal entre locutores socialmente situados.

Filiadas à concepção teórica francesa, conforme Pêcheux (1997), podemos ainda afirmar que o discurso não é nem língua, nem fala. Não é a reabilitação da fala. O discurso é compreendido a partir do fenômeno da linguagem buscado não apenas na língua, mas em outras dimensões além da dicotomia língua/fala, mais especificamente verificáveis em marcas sociais, históricas, ideológicas, psíquicas, nos fios discursivos de sujeitos que interagem em situações concretas. São essas marcas que nos propusemos a verificar nas formulações discursivas de nosso corpus, composto por blocos/eixos de questões, que foram realizadas entre os meses de março a julho de 2007, com grupos familiares integrantes do contexto educacional das escolas do Assentamento de Reforma Agrária Gleba Mercedes V - Núcleos Campos Novos e Agrovila. As entrevistas, na modalidade semi- 
estruturada, foram concebidas como uma atividade interativa na qual as pesquisadoras e os participantes produziram coletivamente descrições contextuais, construíram posições enunciativas, negociaram modos de compreensão. "Esta concepção auto-organizacional, inspirada na etnometodologia, trata os objetos de discurso, as competências, os interlocutores, os contextos, como não pré-definidos ou dados a priori, mas como se constituindo mutuamente e localmente" (Mondada, 1997: p.61).

Essa conceituação de entrevista, que se baseia em uma concepção interativa e praxeológica do discurso, é vista não como um produto estático, mas como um processo dinâmico, constitutivamente ligado às situações em que aparece no fio de um trabalho de negociação, de construção interativa, de elaborações coletivas. Nesse contexto, a materialidade discursiva e analítica construída por meio das entrevistas realizadas com grupos familiares, que residem no Assentamento de Reforma Agrária Gleba Mercedes V, tem o intuito de refletir e promover mudanças no projeto de educação escolar para o campo, o que vem ao encontro da Resolução CNE/CEB n ${ }^{\circ}$ 1, de 03 abril de 2002, que institui as Diretrizes Operacionais da Educação Básica para as Escolas do Campo. Tais Diretrizes Operacionais significam um ponto de inflexão importante na relação Estado-Sociedade na medida em que consolidam e materializam direitos.

Pelo trabalho que desenvolvemos de ensino, pesquisa e extensão na Educação do Campo identificamos que algumas organizações e programas são protagonistas na elaboração desses referenciais de educação e de currículo, dentre as quais podemos citar: MST, CONAQ CONTAG, PRONERA MOC SERTA, IRPAA, RESAB, CEFFAS, CAATINGA, ASSESSOAR, além de iniciativas das Secretarias Municipais e Estaduais de Educação e de Universidades, que buscaram desconstruir a lógica monocultural e tradicional curricular, da inadequação dos conteúdos escolares e sua organização em relação às demandas da vida dos sujeitos do campo, as formas de relacionamento entre a escola e a comunidade e a incorporação de novos saberes e espaços que são importantes para a formação e aprendizagem dos sujeitos. (MUNARIM, 2006: p.05) 
Dessa forma, reiteramos a importância de dar voz à comunidade assentada. Pais e mães, presidentes de associações/cooperativas e alunos e alunas da Educação de Jovens e Adultos sabem das necessidades e anseios que permeiam a sua realidade escolar, são, portanto, elos importantes e que devem ser ouvidos para a efetiva formulação de propostas que culminem com a elaboração de currículos para a educação do campo. É o que Silva (2006: p.09) denomina como "concepção de currículo numa perspectiva de rede de significação, de encontros que entrelaçam as práticas educativas escolares com a vida dos sujeitos". Entendemos o currículo, assim, como uma construção social, multicultural, que pressupõe o envolvimento em relações de poder, de identidades e de práticas sociais de significação.

Para tanto, ainda de acordo com Munarim (2006), há que se instituir, na estrutura das instituições de ensino superior brasileiras, e mesmo em escolas de nível médio, processos de formação inicial de educadores/as do campo. Portanto, em consonância com esse autor, pretendemos, com nosso trabalho de pesquisa, 'contaminar' as Universidades a trabalharem, estudarem e pesquisarem a educação do campo como uma ação formadora e com o propósito de levar a academia a assumir a educação do campo.

\section{Contexto socio-histórico: Assentamento de Reforma Agrária Gleba Mercedes V}

O Assentamento de Reforma Agrária Gleba Mercedes V encontrase localizado a $95 \mathrm{~km}$ do Centro de Sinop, sentido BR $163-220^{7}$, na zona rural. Está dividido em 9 (nove) núcleos, dos quais 2 (dois) já se encontram povoados, respectivamente: Núcleo Agrovila e Núcleo Campos Novos. Foi integrante de um projeto de colonização idealizado pela iniciativa privada, a do núcleo Gleba Celeste, que titulou essas terras integrantes do Norte mato-grossense entre as décadas de 50 e 60 do século XX e vendeu-as a pequenos/as proprietários/as rurais.

7. Estrada que dá acesso ao Assentamento. 
Todavia, vale ressaltar que a ocupação dessa região, que se intensifica na década de sessenta, é resultado do estímulo federal à colonização de toda a Amazônia Legal ${ }^{8}$, considerada até então uma região distante e inacessível. Um dos primeiros programas implantados que objetivava ocupar os espaços do imenso território florestal foi o Programa de Integração Nacional - PIN, desenvolvido com o propósito de promover uma rápida integração da Amazônia matogrossense à economia nacional. Dentre as atividades propostas pelo PIN destaca-se a construção das rodovias Transamazônica e CuiabáSantarém, o que estimula a colonização e a exploração econômica das áreas 'desapropiadas' ao longo destas rodovias.

A intensificação da ocupação, incitada pela política agrária do regime militar, contudo, acabou por despertar o interesse do poder do latifúndio, das grandes empresas nacionais e multinacionais, assim como o desenvolvimento de projetos agrícolas, agroindustriais e agropecuários, financiados pelo Governo.

O primeiro governo militar, devido às condições do país e às pressões americanas, elaborou um projeto de reforma agrária moderado. Transformado na Lei $n^{\circ} 4.504$, de 30 de novembro de 1964, nascia o Estatuto da Terra, criando dois órgãos: o Instituto Brasileiro de Reforma Agrária (IBRA), para cuidar da reforma da estrutura fundiária, e o Instituto Nacional de Desenvolvimento Agrícola (INDA), voltado para o processo de colonização. Esses órgãos sofreram forte pressão do setor latifundiário. Posteriormente foram unificados, surgindo o Instituto Nacional de Colonização e Reforma Agrária (INCRA), em 1970. Levantamentos iniciados pelo IBRA e depois pelo INCRA-1967, 1972 e 1976 - demonstraram um domínio completo dos latifúndios no território brasileiro, que não eram cultivados intensamente, impedindo milhões de trabalhadores de terem acesso a terra e à produção. Os minifúndios, mesmo em maior número, ocupavam áreas pequenas e

8. A região Norte mato-grossense está inserida em uma ampla região denominada Amazônia Legal, área que ocupa 61\% (sessenta e um por cento) do território brasileiro, criada para efeito de ação governamental, possuindo leis diferenciadas do restante do país em relação a incentivos fiscais, e que hoje é composta pela superfície total dos estados do Acre, Rondônia, Amazonas, Pará, Mato Grosso, Tocantins e, parcialmente, o Estado do Maranhão (a oeste do meridiano $44 \mathrm{~N}$ ) e norte de Goiás. (Pitombo-Oliveira, 2007: p. 35) 
respondiam pelo grande volume da produção brasileira de alimentos. Tal constatação teve que ser abafada. (Gaspar, 2010. Grifo da autora)

Dessa forma, o Norte de Mato Grosso transforma-se em palco de latifúndios enormes, que se apoderam, inclusive, de terras de posseiros/as e índios/as para expandir seus domínios. Do mesmo modo, forçavam a venda das pequenas propriedades ou mesmo expulsavam seus donos e donas do local onde viviam. É nesse contexto que as terras que hoje integram o Assentamento de Reforma Agrária Gleba Mercedes V foram, ainda na década de 60, adquiridas pela empresa Mercedes Benz ${ }^{9}$ do Brasil, que as contraiu de pequenos proprietários, num total de 50 (cinquenta) propriedades, perfazendo um total de aproximadamente 500.000 (quinhentos mil) hectares. Como registra Peripoli (2008: 168):

Esta área nunca foi, de fato, ocupada pela empresa. Em 1974 foi vendida a um particular, corretor, e a compra avalizada pelo CBPO (Companhia Brasileira de Projetos e Obras). Como não houve a quitação do débito, a CBPO quitou a conta e ficou com toda a área. Esta empresa, formada por uma família paulista, distribuiu as terras entre os herdeiros e várias empresas/fazendas foram constituídas. Estas, por sua vez, foram, ao longo dos anos, sendo vendidas a terceiros. Uma dessas propriedades foi desapropriada pelo Incra, mais especificamente a Fazenda Sequóia e dividida em várias áreas. Uma destas áreas veio a constituir-se no Assentamento de Reforma Agrária Gleba Mercedes V.

O Assentamento surgiu, então, oficialmente em 1997, durante o Governo de Fernando Henrique Cardoso (1995-2002). Foi instituído pelo Instituto Nacional de Colonização e Reforma Agrária - INCRA e destinado a receber, preferencialmente, pessoas que estavam com dificuldades econômicas na zona urbana de Sinop. No entanto, a distância e as precárias manutenções das vias de acesso a este Assentamento foram as primeiras dificuldades encontradas por todos aqueles que aceitaram o desafio de residir nesse espaço.

9. Empresa multinacional automobilística alemã que iniciou suas atividades no final do século XIX e traduz o primeiro capítulo da motorização veicular no mundo. 
As terras do Assentamento inicialmente continham grande parcela de mata nativa intactas, que foram e continuam sendo devastadas, queimadas ou derrubadas para a ocupação humana, bem como para a agricultura e para a agropecuária. As primeiras pessoas que foram ocupar a terra a elas reservada extraíram a madeira nobre, vendendo-a para as indústrias madeireiras. Para a extração da madeira, as indústrias responsabilizavam-se em fazer as estradas, visto que necessitavam de espaço para a passagem de máquinas e caminhões que importavam para a retirada da madeira, por esta razão surgiram várias estradas que cortam ainda hoje a região: foram feitas pelas empresas madeireiras obedecendo aos traçados que lhes interessavam para chegar à matéria prima para a indústria. Marcados pelo passado de devastação, os moradores das comunidades do Assentamento continuam com a prática de incêndios florestais que consomem parte da vegetação, algumas em estado de recuperação, manchando de cinza, às vezes, grandes áreas de mata. Contudo, há áreas verdes ainda preservadas, que guardam fauna e flora originais. Áreas estas que poderiam servir para um trabalho de preservação e ponto de partida para a (re)tomada da consciência ambiental.

Na tentativa de retirar da terra a sobrevivência, os/as moradores/ as da Gleba Mercedes V iniciaram um tipo de agricultura de produção de gêneros alimentícios, objetivando, além do consumo da unidade familiar, a venda de determinados produtos para os centros urbanos. Tal tentativa de implantação visa garantir recursos necessários para a manutenção das pessoas no local, assim como outras tentativas foram implementadas, gerando uma variedade grande de projetos, alguns, inclusive, com planejamentos inviáveis ou não executáveis.

Pudemos observar em nossas muitas visitas ao Assentamento a existência de agrupamentos de agricultores/as e pecuaristas, formando diversas associações (algumas com o propósito de formar cooperativas) com propostas diversas. Nesses agrupamentos há os que se dedicam à criação de gado de corte para abastecer as indústrias de carne da região; outros tentam a monocultura da soja; a maioria dos agricultores, no entanto, dedica-se à produção de gêneros alimentícios para seu consumo (mandioca, batata, milho, feijão, arroz...) e frutas 
(maracujá, melancia, abacaxi...), com a finalidade de abastecer os supermercados da cidade de Sinop. As vias de acesso, todas com estradas sem pavimentação, permanecem, todavia, um problema para o escoamento da produção dos agricultores/as e pecuaristas.

Vale ressaltar que percebemos distintas realidades nos dois núcleos, Agrovila e Campos Novos, em que realizamos a pesquisa de campo, realidades estas que se traduzem no modo de vida e de organização dessas comunidades assentadas.

\section{Sentidos: uma trama interdiscursiva}

Com relação às escolas dos núcleos que dialogamos, destacamos que a primeira, do Núcleo Agrovila, funciona como extensão ${ }^{10}$ da Escola Estadual Ênio Pipino, que se localiza no centro da cidade de Sinop/MT, e a segunda, do Núcleo Campos Novos, representa uma extensão da Escola Municipal de Educação Básica "Wilibaldo Gobbo”, localizada na periferia dessa mesma cidade.

Inicialmente, o diálogo a que nos propusemos sobre educação do campo e sobre política curricular junto às instituições significou, sobretudo, partirmos de um questionamento sobre qual campo falamos. Desse modo, em consonância com Fernandes (1999), compreendemos que o campo não pode ser visto apenas como espaço territorial demarcador de área, mas como espaço social com vida, identidade cultural própria e práticas compartilhadas por aqueles que as vivem. E, nesse contexto, os saberes são produzidos e evidenciados nos discursos dos sujeitos sociais que constroem essa realidade e fazem a história.

São, portanto, os saberes produzidos que interessaram à nossa pesquisa e nos levaram à reflexão sobre a educação ${ }^{11}$ que deveria

10. As duas escolas do Assentamento respondem administrativamente às escolas urbanas citadas, bem como se vinculam aos seus respectivos Projetos Políticos Pedagógicos.

11. De acordo com Macedo (2001), compreendemos que a educação deve ser vista não apenas como dimensão do conhecimento escolar hegemônico, mas fundamentalmente no processo através do qual os praticantes do currículo (re) significam suas experiências. 
conceber o campo como espaço de vida e resistência, que contemplasse o modo de vida dos sujeitos, não somente dos professores e professoras, dos coordenadores e das coordenadoras, dos alunos e alunas, mas também dos trabalhadores e trabalhadoras rurais (dos assentados/ as). Assim, quando nos referimos à escola do campo voltamo-nos à realidade dos sujeitos do campo (práticas sociais) como ponto de partida e de chegada e à concepção político-pedagógica, que deveria expressar a luta desses sujeitos pelo direito à educação que, conforme Munarim (2006: p.05), desconstrua "a lógica monocultural e tradicional curricular", e que, de acordo com Machado (2006: p.03), deva "construir as condições para que se estabeleça de fato a relação da escola com a vida".

Para que essa relação da escola com a vida aconteça é necessário legitimar a participação dos sujeitos sociais mediante a incorporação do "jeito de viver" desses sujeitos à produção e organização curricular multicultural, para o enriquecimento das experiências e a valorização dos modos de vida. Com tal propósito, portanto, entrevistamos grupos familiares (trabalhadores e trabalhadoras rurais na posição de pais e mães de alunos ou alunas; presidentes de associações/cooperativas e alunos e alunas da Educação de Jovens e Adultos), por compreendermos que estes integram e constituem a relação interdiscursiva ${ }^{12}$ entre a diversidade de saberes e as múltiplas formas de conhecimentos nas comunidades onde vivem.

Nesse sentido, tais saberes e conhecimentos podem e devem ser incorporadas à organização curricular, de acordo com as demandas da vida desses sujeitos que importam para a formação e aprendizagem de alunos e alunas do Assentamento. Imbuídas desse objetivo, fez-se necessário, inicialmente, estabelecermos relação com o projeto de ocupação dos núcleos e com os/as parceleiros/as que deram início a esse projeto.

Os parceleiros do Assentamento de Reforma Agrária Gleba Mercedes V são originários de diferentes regiões do país. São trabalhadores, filhos de agricultores que um dia, pelos mais diversos motivos, viram-se obrigados a deixar o campo (a "roça") e buscar outras formas de "ganhar a vida"

12. Equivale à memória do dizer, de acordo com Orlandi (2007) 
e, em muitos dos casos, longe da terra. Até chegarem à condição de parceleiros todos têm uma trajetória de vida muito semelhante, fortemente marcada por constante processo de expropriação. (PERIPOLI,2008, p.174-175)

Como se pode observar, as características mais comuns dos nossos sujeitos "parceleiros" 13 são as que os identificam como trabalhadores/as que se encontram à margem do sistema econômico, duplamente expropriados, do campo e da cidade, e que se veem diante de um novo recomeço, que os colocam agora na condição de pequenos proprietários. Em geral, possuem pouca ou nenhuma escolaridade e provêm, na sua maioria, de experiências com trabalhos braçais e pouco remunerados. Desse modo, é importante refletirmos sobre o respeito e a valorização da multiplicidade de saberes/conhecimentos/ experiências como ações educativas, pois a educação no campo ocorre tanto em espaços formais como fora da escola. E, de acordo com os pressupostos da Análise de Discurso, não há como negar saberes, conhecimentos, valores, habilidades, disseminados pela memória coletiva. Enfim, os modos de vida dos sujeitos que vivem no campo. Nesse contexto, não são apenas os conhecimentos tidos como conteúdos escolares universais e instituídos por currículos oficiais, trabalhados em sala de aula, os únicos e necessários à educação do campo, mas também os saberes construídos na família, na convivência social, na cultura, no lazer, nos movimentos sociais e em qualquer tipo de organização na comunidade, ou seja, a organização curricular das escolas do campo não pode desconsiderar as condições e lugares de produção de novos sentidos.

A seguir, pautadas no enfoque educacional, sócio-cultural e em conceitos básicos da Análise de Discurso de linha francesa, interpretamos os discursos dos sujeitos sociais acima citados a partir das filiações discursivas em que se inscrevem no intuito de apreendermos o que dizem ou o que deixam de dizer. Para tanto,

13. Conforme o Art. $4^{\circ}$ Inciso VII do Estatuto da Terra - Lei 4504/64 | Lei n ${ }^{\circ} 4.504$, de 30 de novembro de 1964, parceleiro é aquele que adquire lotes ou parcelas em área destinada à Reforma Agrária ou à colonização pública ou privada. 
algumas reflexões iniciais fizeram-se importantes para o olhar que se lançaria ao corpus discursivo transcrito nas formulações ${ }^{14}$, tais como: os grupos familiares consideram importante que os saberes e os demais elementos sócio-culturais, que constituem os seus modos de vida, sejam (re)significados pela escola? Esses saberes são relevantes e pontuados no atual currículo escolar?

E, ainda, como as escolas têm se organizado para a promoção de uma educação que seja no e do campo, que leve em consideração o direito do povo que lá vive a ter uma educação de qualidade, vinculada à sua cultura e às suas necessidades humanas e sociais? Como os fundamentos dos movimentos sociais do campo ou de outras organizações na comunidade enquanto práticas sócio-políticas e culturais constitutivas manifestam-se nas ações pedagógicas escolares? Salientamos que tais reflexões foram norteadoras do processo analítico e dos objetivos propostos pelo projeto de pesquisa. Os recortes de formulações que transcrevemos e analisamos abaixo acentuam essas inquietações suscitadas e apontam, nos efeitos de sentido apreendidos, possíveis respostas.

\subsection{Formulações discursivas (Núcleo Campos Novos): te- ceres analíticos}

Destacamos, aqui, apenas um esboço dos resultados, pois, como já dissemos, limitamo-nos ao espaço do artigo ${ }^{15}$. Dessa forma, optamos por trazer ao corpo analítico desse artigo quatro apanhados de formulações, duas de cada núcleo de pesquisa: Campos Novos e Agrovila. Vale ressaltar, ainda, que as entrevistas foram coletadas

14. Referem-se aos recortes das entrevistas que compõem o corpus e a rede interdiscursiva de análises.

15. O trabalho analítico completo de todas as formulações selecionadas e de todos os segmentos entrevistados encontra-se em CASTILHO, Maria de F. (Org.). Relatório Final do Projeto SABERES DA TERRA: dos discursos dos sujeitos sociais à multiplicidade de saberes para a (re) significação do currículo da educação do campo. Sinop/MT: UNEMAT, 2010. (Relatório de atividades e análises de projeto) 
nas escolas desses núcleos com os grupos familiares que se fizeram presentes ao atender os convites/chamados para serem sujeitos de pesquisa, ou em visitas aos moradores dessas comunidades, os quais prontamente contribuíram com os resultados que ora se apresentam.

$\mathrm{F}(01)$

Eu vejo sobre a educação um ponto bastante crítico para as crianças que participam desta escola, pois é muito longe... . Hoje eu peguei o ônibus da escola para vir aqui, 5 h e $15 \mathrm{~min}$ da manhã e foram todas as crianças, eu parei no mercadinho, no Caldeirão, e as crianças continuaram.

$\mathrm{F}(02)$

A secretaria está envolvida na questão de estrada, porque tudo depende deles... então tá tudo abandonado, nós ficamos dois dias sem ter aula, por não ter caixa reservatório...

$\mathrm{Na} F(01)$ pode-se verificar o retrato dessa escola rural, que destaca: a falta de recursos, a problemática da estrutura física, dificuldades no deslocamento dos alunos e alunas.

Este cenário desenhado pela formulação é ainda uma realidade bastante frequente no meio rural e bem mais saliente nos movimentos populares de assentamento. Isso nos remete às reflexões e inquietações de Werebe (1995:277), "nestas condições, cabe indagar se a multiplicação de escolas constitui um atraso para o nosso ensino ou, se ao contrário, apesar das condições precárias em que se realizam, podem ser consideradas como uma 'inovação', como um progresso."

Não se trata aqui de sermos favoráveis ou não à propagação e disseminação de instituições de ensino nos lugares mais inusitados e geograficamente "menos favoráveis", tais como as escolas do Assentamento de Reforma Agrária Gleba Mercedes V, no entanto, os questionamentos de Werebe são extremamente procedentes e relevantes quando observamos que a quantificação da expansão do ensino, infelizmente, não foi acompanhada por um planejamento 
adequado que atendesse as prioridades qualitativas da educação e primasse por condições mínimas de infraestrutura.

Essa realidade pode ser explicada pelo baixíssimo investimento nas políticas educacionais oficiais, fato que, aliado ao crescimento da população escolar, tornou mais evidente a inadequação e a ineficiência dos agentes responsáveis pelas ações educativas no país. Os precários recursos destinados ao ensino agravam as deficiências da educação do campo não só nos aspectos de qualificação humana como também na problemática das estruturas físicas e de transporte.

Nos fios discursivos dessa primeira formulação tal denúncia é evidenciada pelo sujeito-enunciador pontuando-a, inclusive, como prioridade para a manutenção do homem no campo. Reiteramos, nessa perspectiva, que os graves problemas como falta de infraestrutura, locomoção e transporte, precariedade física e material dos estabelecimentos de ensino, falta de política de valorização do magistério e, consequentemente, de formação de docentes, não são recentes na história brasileira. Razões estas que estatisticamente comprovam o êxodo rural, que teve o seu auge nas décadas de 60, 70 e 80 do século passado.

Todavia, desde os anos 60 os movimentos sociais, sindicais e pastorais uniram forças que passaram a ser determinantes na formação política de lideranças do campo, bem como foram os pilares na luta pelo direito de acesso às propriedades rurais. Contudo, a força e a visibilidade desses movimentos, como o próprio texto base da II Conferência Nacional por uma Educação do Campo (2004) relata, só ocorrem na década de 80 . Acrescentamos, ainda, que as maiores conquistas alcançadas no espaço rural são frutos das reivindicações e articulações dos movimentos acima citados e que, atualmente, se fortaleceram com a participação de organizações sociais ligadas ao campo, com as universidades e instituições de formação, ONG' s e mesmo de outros órgãos de gestão pública vinculados à educação e ao campo. No entanto, os problemas de infraestrutura e de transporte escolar são realidades que ainda persistem, como pudemos constatar na formulação 01 e como podemos verificar na citação abaixo.

O Censo Escolar 2002 incorporou o levantamento de dados relativos ao transporte escolar público estadual e municipal. Foi apurado 
o atendimento para 3.557.765 alunos do ensino fundamental e do ensino médio residentes na zona rural. Desse total, 67\% são transportados para escolas localizadas na zona urbana e apenas $33 \%$ para escolas rurais. Essa prática tem gerado um debate intenso, pois enquanto os movimentos sociais e uma série de políticas governamentais buscam fixar o trabalhador rural no campo e assegurar a posse da terra para aqueles que a desejem cultivar, o transporte escolar atua em sentido inverso levando o filho deste trabalhador para os núcleos urbanos. Por outro lado, cabe avaliar se essas escolas urbanas para onde os alunos residentes na área rural estão sendo transportados estão localizadas em municípios com características "realmente urbanas" ou "meandros rurais imprecisos ou ambíguos”. (VEIGA, 2001: 78)

O sujeito da $F(02)$ legitima ainda mais o estado de precariedade do transporte público ao dizer “... a secretaria está envolvida na questão de estrada, porque tudo depende deles...” Aqui cabe ressaltar que não basta apenas a implantação de uma escola rural, fatores como o transporte e a manutenção de estradas que permitam segurança no deslocamento para o acesso à escola são pontos imprescindíveis a serem tratados pelos setores políticos competentes. O desejo do sujeito dessa formulação representa o anseio da comunidade agrária de escolarização e efetiva inserção no processo pedagógico da educação formal, reiterado pela denúncia de que: “... nós ficamos dois dias sem ter aula”.

Essa tomada de consciência vivida por homem e mulheres que trabalham a terra, quanto à vida que levam e a precariedade do ensino para seus filhos, vem ao encontro da dura realidade das famílias rurais que insistem na tentativa de se fixar e permanecer no campo. Torres (1994: 42), ao defender a ideia de permanência do pequeno agricultor no campo, afirma que "para que se defenda a permanência do produtor familiar no campo, importa situar esse produtor num patamar diferente daquele em que ele se encontra hoje; é inadmissível querer mantê-lo num estado de atraso absoluto, negando-lhe as condições de desempenho adequado e eficaz". Nesse ponto, o Estado não pode se omitir em desenvolver uma política integrada com os Ministérios e Secretarias da Saúde, da Educação, da Cultura, do Meio ambiente, 
dentre outras, para viabilizar a resolução dos problemas da educação e da sustentabilidade dos povos do campo.

A realidade que se apresenta para os/as assentados/as de reforma agrária no país não é, portanto, animadora e entusiástica como os movimentos sociais, sindicais e pastorais a idealizaram. Os dados e fatos que constam nas informações oficiais e não-oficias são os que revelam uma (re)produção sistemática da miséria e do descaso das políticas agrárias, que mantém reféns trabalhadores e trabalhadoras rurais à espera de melhores condições de vida e de investimentos em infraestrutura que satisfaçam as suas necessidades. Nesse sentido, as campanhas de mobilização por escolas públicas de qualidade e acessíveis a todos são assuntos geradores de inúmeras manifestações e de embates sociais por certos setores da sociedade civil. Os debates na esfera educacional envolvem quase sempre o papel da educação no desenvolvimento da sociedade e as divergências teóricas de suas proposições são sempre conflitantes frente à realidade educacional que compõe o cenário brasileiro. Wanderley, ao traçar um perfil histórico sobre a escola pública, faz o seguinte comentário:

Após 1964, o Estado vai impor um modelo em que a educação fundamentalmente será colocada a serviço dos interesses econômicos e se realinhará de conformidade com as novas formas de controle social e político. Os autores que publicaram trabalhos de avaliação da política educacional elaborada e executada pelo Estado demonstram que ele atuou em função dos interesses de classe das classes dominantes, o que pode ser percebido nos pronunciamentos oficiais, na legislação, no planejamento, e nos efeitos dessa política na realidade educacional. Esses interesses correspondem aos setores da burguesia nacional, em sua quase totalidade subordinada à burguesia internacional, e a alguns setores de classe média, basicamente intelectual e democrata. (WANDERLEY, 1995: 48)

Essa realidade pouco foi alterada até os dias de hoje. O reflexo da falta de planejamento econômico voltado às políticas educacionais 
no âmbito da educação popular, comprometidas com os interesses das classes populares tanto urbanas quanto rurais, é facilmente observável pela precariedade física e humana de investimentos disponibilizados para as instituições geograficamente mais afastadas de centros urbanos, como nas escolas que constituíram nosso espaço de pesquisa.

Assim, quando os sujeitos/enunciadores das formulações acima interpelam: "Eu vejo sobre a educação um ponto bastante crítico para as crianças que participam desta escola, pois é muito longe...”; “... porque tudo depende deles... então tá tudo abandonado, nós ficamos dois dias sem ter aula, por não ter caixa reservatório...”, compreendemos que o intuito desses apelos pode ser traduzido pela necessidade de realçar ainda mais a sujeição que é imposta ao/á pequeno/a proprietário/a rural, excluído/a, marginalizado/a e esquecido/a. Os sujeitos, ao serem ouvidos, querem expressar a indignação que se evidencia a partir da ausência de investimentos em infraestrutura e disponibilização de recursos como cumprimento das promessas de implantação da escola rural e do próprio Assentamento.

Outro efeito de sentido importante mobilizado é o que atribui à educação um papel importante na vida dos filhos e que pressupõe que no campo essa educação não cumpre sua função social, pois esbarra em diversos empecilhos, tais como o transporte escolar e a distância entre as moradias e a escola. Os sentidos que implicam esta maneira de ver a educação estão na memória prática do dizer, isto é, de acordo com Pêcheux (1983), a memória interdiscursiva encarrega-se de resgatar, na materialidade da língua, as formações imaginárias que regem as formações discursivas ideológicas da qual somos representantes.

É essa memória interdiscursiva corrente da organização escolar e sobre a 'facilidade' que os alunos da cidade têm quanto ao acesso à educação que privilegia a ênfase das políticas públicas e curriculares do pólo urbano em detrimento de um meio rural subordinado e afastado da temática do rural. Estes fatores demonstram, no entanto, que as formações discursivas, mesmo sofrendo alterações significativas ao longo do tempo, permanecem estáveis no imaginário social e reforçam, no entrelace da rede de sentidos interdiscursivos, ainda que 
de forma ambivalente, a importância da escola para a aquisição do conhecimento e de melhores condições econômicas e profissionais.

\subsection{Formulações discursivas (Núcleo Agrovila): teceres analíticos}

O espaço rural, mais do que um perímetro não-urbano, é um espaço de possibilidades que abrange tanto as condições materiais de produção como as relações de interação humana, as quais refletem não apenas estados harmoniosos como também evidências de conflitos e mobilizações de luta pela terra.

\section{(F03)}

...eu acho essa questão da educação do campo, por toda parte tem uma preocupação... na juventude aqui, eles falam "vamos embora", "vamos saî", "vamos picar a mula", e "como que você vai querer crescer?" Então eu acho que tem que ser uma educação que traga esperança prá que os jovens fiquem aqui, estimule ele, que ele possa contribuir, e que ele fique aqui, que isso vá em frente, que ele possa até ir, pra estudar, fazer um curso...

É no contexto comentado acima que o sujeito assentado da $\mathrm{F}(03)$ pensa a atuação escolar, isto é, numa instituição voltada para a realidade agrária através da adaptação do quadro curricular com disciplinas que englobem um contato direto do homem com a terra, ou seja, no meio em que vive. Tal efeito de sentido manifestado nessa formulação está em consonância com as seguintes reflexões trazidas no manual do Ministério da Educação (2002) sobre as diretrizes operacionais para a educação básica nas escolas do campo: "os movimentos sociais do campo propugnam por algo que ainda não teve lugar, em seu estado pleno, porque perfeito no nível das suas aspirações. Propõem mudanças na ordem vigente, tornando visível, por meio das reivindicações do cotidiano, a crítica ao instituído e o horizonte da educação escolar inclusiva." O enunciador da formulação reforça essa necessidade ao preconizar "uma educação que traga esperança prá 
que os jovens fiquem aqui”. Nessas marcas discursivas destaca-se o apelo para que as práticas pedagógicas contemplem o cotidiano da problemática rural e relacionem o planejamento curricular à realidade circundante do espaço produtivo rural. Esse apelo evidencia o efeito de crítica ao instituído e revela uma sabedoria prática de que a educação universalizante não suprime as necessidades inerentes ao meio rural e muito menos serve de parâmetro para uma educação que objetiva ser inclusiva.

A formulação 03 questiona ainda o estímulo recebido na escola para que os jovens assentados permaneçam no campo. Dessa forma, cabe refletir sobre a seguinte questão: a homogeneização do urbano compromete a representação dos saberes rurais? Respostas conclusivas a tal inquietação ultrapassam o limite deste trabalho, mas vale a reflexão de que é necessário não apenas promover um lugar de encontro entre o rural e o urbano em que se possa trabalhar as especificidades, mas também promover um resgate no processo de constituição de identidades em que o homem e a mulher do campo sejam autônomos e sujeitos nas representações de direito e cidadania. Cabe, então, às organizações escolares rurais um papel importante na manutenção dos assentados no campo em face das transformações do mundo contemporâneo.

\section{(F04)}

(...) Eu acho que não tem um projeto, como foi falado, direcionado pro campo, até uma vez veio o professor Edvaldo e disse que ia levar as crianças prá escola, prá Sinop, prá eles terem o mesmo que lá tinha, tentar passar o mesmo, porque aqui não é diferenciado.

Tendências recentes no âmbito da organização curricular visam a oferecer alternativas para as diferentes propostas e planejamentos pedagógicos, todavia, ainda há uma resistência grande, como podemos observar em F(04), em se implantar especificidades de abordagens curriculares multiculturais em detrimento da generalização e da homogeneidade de um planejamento global. Ferretti 1995: 65-67 chama a atenção para estas tendências: " alguns dos desenvolvimentos 
pedagógicos recentes referem-se à organização do currículo. Tais desenvolvimentos expressam-se sob a forma de diferentes padrões curriculares, comprometidos com particulares concepções de educação"

Essa apresentação dos moldes curriculares nos mostra, por Ferretti, que os desenvolvimentos pedagógicos da escola do campo poderiam estar aptos a se comprometer com as especificidades das concepções de educação. Pois, a mudança do tipo de conteúdo a ser abordado pode, por exemplo, ser proposta tanto pelo "core currículo" quanto pelo "currículo de atividades", porque a organização de tais currículos teria como prioridade levar em conta fenômenos sociais e o interesse e as necessidades dos/as alunos/as. É este desenvolvimento, portanto, que deve ser incorporado pela escola rural, ou seja, a escola do campo deve repensar a estrutura curricular propondo a integração de conteúdos ou objetivos à realidade do campo. Compreendemos que só assim será possível, conforme acentua o sujeito da formulação, a instituição de "um projeto (...) direcionado pro campo" em oposição aos padrões curriculares tradicionais que compartimentalizam as disciplinas e se esquecem dos reais problemas sociais e necessidades de seus aprendizes.

\section{Gestos de interpretação: sentidos finalizadores}

Ao término das etapas desse projeto de pesquisa, objetiva-se dar continuidade à ampla socialização dos resultados analíticos apreendidos no corpus. Salientamos, de antemão, o trabalho desenvolvido pelas pesquisadoras ao acompanharem as práticas educacionais desenvolvidas nas duas escolas do Assentamento, Núcleos Campos Novos e Agrovila, no que diz respeito às concepções de educação, função social da escola, procedimentos didático-metodológicos, e oportunizarem aos grupos familiares a se manifestar, permitindolhes apresentar os problemas reais, as experiências frustradas, as dificuldades que os envolvem, bem como trazer nas manifestações discursivas sugestões, propor mudanças e reivindicações. 
A divulgação desse trabalho iniciou-se pelo encaminhamento dos resultados às Secretarias Municipal e Estadual de Educação de Sinop, mais especificamente em reuniões feitas com os profissionais responsáveis pela elaboração de propostas curriculares, e por debates acadêmicos promovidos na Universidade Estadual de Mato Grosso, o que culminou com a aprovação recente do Curso de Licenciatura em Pedagogia do Campo, que iniciará suas atividades no segundo semestre de 2011. A partir desses encaminhamentos, espera-se, efetivamente, contribuir com a (re)construção da identidade pessoal dos sujeitos sociais do campo, potencializando-os a se descobrirem como seres históricos e construtores de currículos pela legítima participação no processo educativo na sua comunidade e a contemplarem nas políticas educacionais as particularidades históricas, sociais, culturais e ecológicas que diferenciam o campo da cidade.

Nesta perspectiva, acentua-se, entretanto, a complexidade que se apresenta nesse contexto e entre os sujeitos participantes desse espaço de diversidade, o que nos leva a compreender que campo e cidade devem ser interpretados como dois pólos que se complementam, apesar de suas especificidades, sendo, portanto, interdependentes para a articulação de saberes e de conhecimentos. Acreditamos, ainda, que a ampla divulgação dos resultados e novos gestos de interpretação que podem ser suscitados em debates e eventos, tanto no espaço acadêmico quanto nos espaços dos movimentos e organizações sociais, possam implementar e promover mudanças no currículo dos Cursos de Licenciatura, mais especificamente às abordagens relacionadas à educação do campo, bem como dar impulso a reflexões sistemáticas da política educacional que mobiliza a construção dos currículos escolares.

Recebido em: 16/03/11 Aprovado em: 09/05/11 neinph@yahoo.com.br 


\section{Referências Bibliográficas}

BRASIL. Ministério da Educação. II Conferência Nacional por uma Educação do Campo. Por uma política pública de educação do campo. (Texto base). Luziânia, GO, 2 a 6 de agosto de 2004.

. Ministério da Educação. Diretrizes Operacionais para a Educação Básica nas Escolas do Campo. MEC. RESOLUÇÃO Nº 01 DE 03/04/2002. Diretrizes operacionais para a educação básica do campo. Brasília, Imprensa Nacional, 2002.

CAMINI, Isabela. O cotidiano pedagógico de professores e professoras em uma escola de assentamento do MST: limites e desafios. Porto Alegre: UFRGS, 1998. (Dissertação de Mestrado).

CARDOSO, Sílvia Helena B. Discurso e ensino. $2^{\text {a }}$ ed. Belo Horizonte: Autêntica/FALE-UFMG, 2003.

CASTILHO, Maria de F. (Org.). Relatório Final do Projeto SABERES DA TERRA: dos discursos dos sujeitos sociais à multiplicidade de saberes para a (re) significação do currículo da educação do campo.Sinop/MT: UNEMAT, 2010. (Relatório de atividades e análises de projeto)

FERRETTI, Celso João. A inovação na perspectiva pedagógica. In: GARCIA, Walter E. (Org.). Inovação educacional no Brasil: problemas e perspectivas. 3. ed. Campinas, SP: Autores Associados, 1995.

FERNANDES, Bernardo Mançano. Contribuição ao estudo do campesinato brasileiro. Formação e territorialização do movimento dos trabalhadores rurais sem terra - MST. 1979-1999. São Paulo: USP, 1999. (Tese de Doutorado).

Gaspar, Lúcia. Reforma Agrária no Brasil. Pesquisa Escolar On-Line, Fundação Joaquim Nabuco, Recife. Disponível em: < http://www.fundaj.gov. br $>$. Acesso em 11 de maio de 2011, às $22 \mathrm{~h}$ e $17 \mathrm{~min}$.

GIROUX, H. A. Os professores como intelectuais: rumo a uma pedagogia crítica da aprendizagem. Porto Alegre: Artes Médicas, 1997.

INSTITUTO BRASILEIRO DE GEOGRAFIA E ESTATÍSTICA. Resultados do Censo. Dados do censo 2010 publicados no Diário Oficial da União. Rio de Janeiro: Nov. de 2010. Disponível em:

http://www.censo2010.ibge.gov.br/dados_divulgados/index. php? uf $=51$. Acesso em 10 de maio de 2011, às $15 \mathrm{~h}$ e $36 \mathrm{~min}$. 
JUSBRASIL. Legislação. Estatuto da Terra - Lei 4504/64 | Lei no 4.504, de 30 de novembro de 1964. Disponível em http://www.jusbrasil.com.br/ legislacao/104451/estatuto-da-terra-lei-4504-64. Acesso em 02 de junho de 2011, ás $15 \mathrm{~h}$ e $02 \mathrm{~min}$.

MACEDO, E. O que significa currículo disciplinar? In: CANDAU, V. M. (Org.). Linguagens, espaços e tempos no ensinar e aprender. Rio de Janeiro: DP\&A, 2001. p. 181-88.

MACHADO, Ilma. F. A construção de um projeto político-pedagógico para a escola do campo. In: I SEMINÁRIO DE EDUCAÇÃO DO CAMPO DO NORTE DE MATO GROSSO E II SEMINÁRIO DE ANÁLISE DE DISCURSO DA UNEMAT/SINOP, fev.2006.

MAINGUENEAU, D. Novas tendências em análise de discurso. Trad. Freda Indursky. Campinas: Pontes/Editora da Universidade Estadual de Campinas, 1997.

MONDADA, Lorenza. A Entrevista como Acontecimento interacional: abordagem lingüística e conversacional. Campinas, SP: Revista RUA, 1997, p. 59-86.

MUNARIN, Antônio. Elementos para uma política pública de educação do campo. In: I SEMINÁRIO DE EDUCAÇÃO DO CAMPO DO NORTE DE MATO GROSSO E II SEMINÁRIO DE ANÁLISE DE DISCURSO DA UNEMAT/Sinop, fev.2006.

ORLANDI, Eni Puccinelli. Interpretação; autoria, leitura e efeitos do trabalho simbólico. $5^{\mathrm{a}}$ ed. Campinas/SP: Pontes Editores, 2007.

.Discurso e texto: formação e circulação dos sentidos. Campinas, SP: Pontes, 2001.

. Análise de Discurso: princípios e procedimentos. Campinas, SP:

Pontes, 2000.

PÊCHEUX, M. (1938-1983). O Discurso: Estrutura ou Acontecimento. Trad. Eni P. Orlandi. 2. ed. Campinas, SP: Pontes, 1997.

PÊCHEUX, Michel; FUCHS, C. A propósito da Análise Automática do discurso: atualização e perspectiva. IN: GADET F. \& HAK (Org.). Por uma análise automática do discurso: uma introdução à obra de Michel Pêcheux. Campinas, SP: UNICAMP, 1993.

PERIPOLI, Odimar João. Expansão do Capitalismo na Amazônia Norte 
Mato-grossense: a mercantilização da terra e da escola. Programa de PósGraduação em Educação - PPGEDU da Universidade Federal do Rio Grande do Sul - UFRGS, Porto Alegre, 2008. Tese (doutorado em educação).

PITOMBO-OLIVEIRA, Tânia. Fronteira Discursiva: o paralelo $13^{\circ}$ e os sentidos da exclusão. Cáceres/MT: Editora Unemat, 2007.

SILVA, Maria do Socorro. Reflexões sobre currículo e educação do campo. IN: I SEMINÁRIO DE EDUCAÇÃO DO CAMPO DO NORTE DE MATO GROSSO E II SEMINÁRIO DE ANÁLISE DE DISCURSO DA UNEMAT/ SINOP, fev.2006.

TORRES, Artemis A. M. Mato Grosso em movimentos: ensaios de educação popular. Cuiabá: EdUFMT, 1994.

WANDERLEY, Luiz Eduardo W. Parâmetros sociológicos da inovação. In: GARCIA, Walter E. (coord.). Inovação educacional no Brasil: problemas $e$ perspectivas. 3. ed. Campinas, SP: Autores Associados, 1995.

WEREBE, Alcance e Limitações da Inovação Educacional. In: GARCIA, Walter E. (coord.). Inovação educacional no Brasil: problemas e perspectivas. 3. ed. Campinas, SP: Autores Associados, 1995.

VEIGA, José E. O Brasil rural ainda não encontrou seu eixo de desenvolvimento.

Revista Estudos Avançados 15(43) 2001, p. 101-119. Ministério do Desenvolvimento Agrário. Brasília, 2001. 